\title{
ETNICIDADE: IDENTIDADE E DIFERENÇA ${ }^{1}$
}

\author{
Stuart Hall \\ Tradução de Ana Carolina Cernicchiaro*
}

Eu escolhi falar sobre questões de identidade e etnicidade, primeiro, porque estas questões vieram subitamente à tona na discussão e no debate intelectual e crítico inglês. E, segundo, porque a relação entre as identidades culturais e as etnicidades está também na agenda política britânica neste momento. Eu tentarei dizer no decorrer da minha fala porque eu acho que questões de identidade estão novamente em jogo conceitual e politicamente.

\section{O RETORNO DA IDENTIDADE}

$\mathrm{Eu}$ estou interessado no que algumas vezes é chamado de "retorno da questão da identidade" - não que ela tenha ido embora algum dia, mas voltou com força particular. Este retorno tem algo a ver com o fato de que a questão da identidade se concentra naquele ponto onde toda uma série de diferentes desenvolvimentos da sociedade e um conjunto de discursos correlacionados se interligam. A identidade emerge como uma espécie de espaço desestabilizado, ou uma questão não resolvida nesse espaço, entre diversos discursos interligados. Minha proposta é demarcar alguns desses pontos de intersecção, especialmente em torno de questões de identidade cultural, e explorá-los em relação ao tema da etnicidade na política.

Deixe-me começar dizendo alguma coisa sobre o que parece ser a lógica pela qual nós temos pensado e falado sobre identidade recentemente. A lógica do discurso identitário assume um sujeito estável, isto é, temos assumido que há algo que nós podemos chamar de nossa identidade, o que, em um mundo que muda rapidamente, tem a grande vantagem de permanecer imóvel. Identidades são uma forma de garantia de que o mundo não está se desmoronando tão rapidamente quanto algumas vezes parece. É um tipo de ponto fixo do pensamento e do ser, uma base de ação, um ponto parado no mundo em transformação. Este é o tipo de garantia última que a identidade parece nos prover.

A lógica da identidade é a lógica de algo como um "verdadeiro eu". E a linguagem da identidade tem sido frequentemente relacionada à procura por um tipo de autenticidade para a própria experiência, algo que me diz de onde eu vim. A lógica e a linguagem da

\footnotetext{
${ }^{1}$ N.T.: "Ethnicity: Identity and Difference" foi publicado na revista Radical America de outubro-dezembro de 1989 (vol. 23 no. 4). Trata-se de uma conferência pronunciada naquele mesmo ano no Hampshire College, Amherst Massachusetts. Agradeço a Catherine Hall por gentilmente permitir à Revista Crítica Cultural a publicação desta versão em português.

* Doutora em Literatura pela Universidade Federal de Santa Catarina (UFSC) e professora do Programa de Pós-Graduação em Ciências da Linguagem da Universidade do Sul de Santa Catarina (PPGCL/Unisul).
} 
identidade é a lógica da profundidade - aqui, no fundo de mim, está meu $\mathrm{Eu}$, o qual eu posso refletir. É um elemento de continuidade. Eu acho que muitos de nós reconhecemos que nossas identidades têm mudado com o tempo, mas temos a esperança ou a nostalgia de que elas mudam na velocidade de um glaciar. Ainda que não sejamos imaturos como éramos quando tínhamos um ano de idade, somos o mesmo tipo de pessoa.

\section{A RUPTURA DA IDENTIDADE}

Então de onde vem a recente ruptura da identidade? O que está deslocando essa profundidade - a origem autônoma, o ponto de referência, a continuidade garantida que há tanto tempo tem sido associada com a linguagem da identidade? O que é isso, da turbulência do mundo em que vivemos, que está progressivamente se refletindo nas vicissitudes da identidade?

Enquanto, historicamente, muitas coisas têm deslocado ou descentralizado o sentido estável de identidade que acabei de descrever, quero focar em quatro grandes descentramentos na vida intelectual e no pensamento ocidental que têm ajudado a desestabilizar a questão da identidade. Eu irei atribuir nomes particulares para três deles, somente por conveniência. Eu não quero dizer que eles fizeram isso sozinhos, mas é relativamente útil sintetizar as ideias vinculando-as a um nome particular. O quarto não pode ser atribuído a um único nome, mas é tão importante quanto.

Marx começa o descentramento desse sentido estável de identidade nos lembrando que sempre há condições para a identidade que o sujeito não pode construir. Homens $e$ mulheres fazem a história mas não sob suas próprias condições. Eles são parcialmente feitos pelas histórias que fazem. Nós somos sempre construídos em parte pelas práticas e discursos que nos fazem, de tal forma que não podemos achar dentro de nós, como indivíduos, sujeitos ou identidades, o ponto de origem pelo qual o discurso, a história ou as práticas se originam. A história deve ser entendida como uma dialética contínua ou uma relação dialógica entre aquilo que já foi feito e aquilo que está fazendo o futuro. $\mathrm{O}$ argumento de Marx desconstrói muitos jogos, mas eu estou particularmente interessado em seu impacto sobre o jogo identidade/linguagem. Marx interrompeu essa noção de sujeito soberano que abre sua boca e fala, pela primeira vez, a verdade. Marx nos lembra que nós estamos sempre submetidos e implicados nas práticas e estruturas de vida de todos.

Segundo, há o deslocamento muito profundo que começa com a descoberta de Freud do inconsciente. Se Marx nos deslocou do passado, Freud nos deslocou por dentro. A identidade está em si mesma baseada no enorme desconhecido de nossa vida psíquica, e não podemos atravessar de um modo simples a barreira do inconsciente para atingi-la. Não podemos ler o psíquico diretamente no social e no cultural. No entanto, a vida social, cultural e política não pode ser entendida exceto em suas relações para as formações da vida inconsciente. Isto desestabiliza em si mesmo a noção de eu, de identidade, como uma entidade completamente autorreflexiva. Não é possível para o eu refletir e saber completamente sua própria identidade já que ela é formada não apenas na linha das 
práticas de outras estruturas e discursos, mas também em uma relação complexa com a vida inconsciente.

Terceiro, nós devemos considerar Saussure e seu modelo de linguagem e linguística que tanto transformou o trabalho teórico. Linguistas saussureanos sugerem que a fala - os discursos, a própria enunciação - é sempre colocada dentro das relações de linguagem. Para falar, para dizer algo novo, nós temos que primeiro nos colocarmos dentro das relações existentes da linguagem. Não há declaração tão inovadora e tão criativa que já não carregue em si os traços de como essa linguagem tem sido falada antes de abrirmos nossa boca. Portanto, estamos sempre dentro da linguagem. Dizer algo novo é antes de tudo reafirmar os traços do passado que estão inscritos nas palavras que usamos. Em parte, dizer algo novo é antes de tudo deslocar todas as velhas coisas que as palavras significam - lutar com um sistema inteiro de significados. Por exemplo, pense no quão difícil tem sido, em nosso mundo, dizer a palavra "Negro" de uma nova maneira. Para dizer "Negro" de uma nova maneira, nós temos que combater todo o resto que "Negro" sempre quis dizer - todas as suas conotações, todas as suas figurações negativas e positivas, a estrutura metafórica do pensamento cristão, por exemplo. Toda a história do pensamento imperialista ocidental é condensada na luta para deslocar o que Negro costumava significar, de forma a fazer isso significar algo novo, de forma que se possa dizer "Negro é lindo" ["Black is beautiful"]. Não estou falando somente das teorias da linguagem específicas de Saussure. Estou falando sobre o que acontece na concepção de identidade quando de repente se entende que sempre se está dentro de um sistema de linguagens que em parte nos fala, em relação ao qual nós estamos sempre posicionados dentro e contra.

Estas são as grandes figuras do modernismo. Nós podemos dizer que se a modernidade liberta a lógica da identidade de que eu estava falando antes, o modernismo é a modernidade experienciada como problema. Na face da promessa do grande futuro da modernidade: "Eu sou, eu sou um homem ocidental, portanto eu sei tudo. Tudo começa comigo". Diz o modernismo: "Calma. E o passado? E as línguas que você fala? E a vida inconsciente que você não conhece? E todas as outras coisas que estão te falando?"

No entanto, há uma quarta força de desestabilização. Pode receber uma variedade de nomes. Se você quiser permanecer na episteme do conhecimento ocidental, você pode dizer Nietzsche. Mas eu quero dizer algo mais. Eu quero falar do descentramento da identidade que surge como consequência do fim da noção de verdade como tendo algo que ver diretamente com o discurso ocidental da racionalidade. Este é o grande descentramento da identidade que é uma consequência da relativização do mundo ocidental - da descoberta de outros mundos, outros povos, outras culturas e outras linguagens. $O$ pensamento ocidental, apesar de seu clamor imperialista para ser $a$ forma de conhecimento universal, de repente aparece como apenas uma outra episteme. Para usar as palavras de Foucault, apenas outro regime de verdade. Ou nas de Nietzsche, não Conhecimento absoluto, não Verdade total, apenas outra forma particular de poder histórico. A ligação entre conhecimento e poder é o que torna esse regime Verdadeiro, o que permite que esse regime reivindique a falar a verdade sobre identidade para todos ao redor do globo. 
Quando essa instalação da racionalidade ocidental começa a ser vista não como absoluta, desinteressada, objetiva, neutra, científica, verdade sem poder, mas como verdade suja, verdade implicada no jogo difícil do poder - essa é a quarta cena que desestabiliza a velha lógica da identidade.

\section{IDENTIDADES COLETIVAS}

Eu tenho falado até agora sobre deslocamentos intelectuais, teóricos, conceituais da noção de identidade, mas eu quero falar sobre alguns dos deslocamentos da identidade que vieram da vida cultural e social, mais do que do pensamento conceitual e teórico. Os grandes coletivos sociais que costumavam estabilizar nossas identidades - os grandes coletivos estáveis de classe, raça, gênero e nação - têm sido, em nosso tempo, profundamente enfraquecidos por desenvolvimentos sociais e políticos.

Toda a aventura do mundo moderno foi, por um bom tempo, bloqueada por essas grandes identidades coletivas. Quando alguém sabia sua classe, sabia seu lugar no universo social. Quando alguém sabia sua raça, sabia sua posição racial na relação hierárquica das grandes raças do mundo. Quando alguém sabia seu gênero, era capaz de se posicionar na enorme divisão social entre homens e mulheres. Quando alguém sabia sua identidade nacional, sabia certamente sobre a ordem social hierárquica do universo. Estas identidades coletivas estabilizaram e organizaram nossa percepção de nós mesmos. Essa lógica de identidade que parecia tão confiante no início da minha fala, era em parte mantida por essas grandes identidades sociais coletivas.

Agora, não é o segredo mais bem guardado do mundo que toda sorte de coisas têm abalado e estremecido essas grandes identidades coletivas, estáveis, sociais do passado. Eu não quero falar de nenhum desses desenvolvimentos em detalhe, mas se você pensa, por exemplo, em classe, certamente não é verdade que, em sociedades como as suas e a minha, questões de classe - de estrutura social e desigualdade social que se ergueram sob a noção de classe - desapareceram. Mas, entretanto, a forma como as identidades de classe foram entendidas e experienciadas, a forma como as pessoas se colocam em relação às identidades de classe, a forma como nós entendemos essas identidades como politicamente organizadas - essas formas estáveis de identidade de classe são muito mais difíceis de encontrar nesse ponto do século XX do que cem anos atrás. De fato, olhando para trás, não estamos certos se as grandes identidades estáveis de classe eram tão estáveis como nós dissemos a nós mesmos. Há um tipo de narrativa de classe que sempre fez o passado parecer mais simples do que provavelmente era. Se você voltar para a vida do século XIX na Inglaterra, perceberá que a classe era algo bastante complexo mesmo naquele momento. No entanto, eu acho que há algum sentido relativo no qual o estadonação, as grandes formações do capitalismo industrial, certamente o modo em que o gênero foi conceitualizado e, mais no final do século XIX, o modo como toda população do mundo pôde ser pensada em termos de uma grande família de raças - eu realmente acho que de alguma forma esses grandes princípios estruturadores, que estão amarrados à questão de nossas identidades sociais e culturais, foram consideravelmente fraturados, fragmentados, prejudicados, dispersados no curso dos últimos cinquenta anos. 
Agora, esta fragmentação da identidade social é uma parte importante da experiência moderna e, se você acredita nisso, pós-moderna. Esse sentido de fragmentação tem uma forma peculiar e particular. Mais especificamente, se eu posso dizer isso metaforicamente, a fragmentação é ao mesmo tempo local e global, enquanto as grandes identidades estáveis não parecem se sustentar.

Veja "a nação". O estado-nação está cada vez mais sitiado pela interdependência do planeta - pela interdependência de nossa vida ecológica, pela enorme interpenetração do capital como força global, pelos modos complexos pelos quais os mercados mundiais ligam as economias atrasadas, nações desenvolvidas e subdesenvolvidas. Estes enormes sistemas estão enfraquecendo cada vez mais a estabilidade de qualquer formação nacional. Os estados-nação estão com problemas, embora eu não vá profetizar que o estado-nação, que tem dominado a história do mundo por tanto tempo, irá se despedir graciosamente.

Por um lado, a nação e todas as identidades que ela envolve parecem ter ascendido - reabsorvidas em grandes comunidades que excedem e interconectam identidades nacionais. Mas ao mesmo tempo há um movimento para baixo. Povos, grupos e tribos que eram previamente explorados em conjunto pelas entidades chamadas estados-nação começam a redescobrir identidades que tinham sido esquecidas. Por exemplo, se você vier para a Inglaterra na esperança de ver uma grande identidade cultural estável chamada "o Inglês" - que representa todos - o que você encontrará no lugar são, por exemplo, escoceses que estão prestes a desprender-se. Eles dizem "somos escoceses e europeus, mas certamente não somos britânicos". E os galeses dirão "também não somos britânicos porque vocês nos esqueceram e também devemos ir para outro lugar".

Ao mesmo tempo o Nordeste e o Noroeste da Inglaterra, que foram deixados para apodrecer pela Sra. Thatcher, também não são mais verdadeiramente britânicos - eles são marginais para todos os outros. Então os velhos sindicalistas e todos os negros também são outra coisa. $\mathrm{O}$ que restou como inglês foi uma pequena ilha em algum lugar em Londres com cerca de 25 almas e o governo Thatcher sobrevoando. E eles continuam se perguntando - não apenas em relação ao resto do mundo mas sobre a maioria das pessoas de sua própria sociedade - "vocês são um de nós?".

As pessoas se sentem ao mesmo tempo partes do mundo e partes de sua vila. Elas têm identidades de vizinhança e são cidadãs do mundo. Seus corpos estão em perigo por Tchernóbil, que não bate na porta e diz "posso espalhar radiação sobre seu território soberano?" Ou, outro exemplo, ano passado nós tivemos o mais quente inverno que eu já vivi na Inglaterra - em parte consequência da destruição das florestas tropicais a milhares de milhas de distância. Uma compreensão ecológica do mundo é uma que desafia a noção de que os estados-nação e as fronteiras de soberania vão manter as coisas estáveis porque eles querem. O universo está chegando!

Por um lado, temos as identidades globais porque temos apostado em algo em comum, por outro lado, só podemos saber de nós mesmos porque somos parte de algumas 
comunidades face-a-face. Isto me traz novamente para a questão do destino da identidade cultural neste redemoinho. Dado esse teórico e conceitual descentramento que eu acabei de falar, dada a relativização das grandes identidades estáveis que nos permitiram saber quem nós somos, como podemos pensar sobre a questão da identidade cultural?

\section{PÓS-IDENTIDADE?: HISTÓRIAS DE FACHADA}

Há uma linguagem para a ideia de prescindir de toda identidade. Esta é a minha referência um tanto quanto desfavorável à versão extrema do pós-modernismo. $\mathrm{O}$ argumento é que o Eu é simplesmente um tipo de significante perpétuo sempre vagando na terra em busca de um significado transcendente que ele nunca pode encontrar - um tipo de existência nômade interminável com indivíduos absolutamente atomizados vagando num vazio plural interminável. Além disso, embora haja certos modos teóricos e conceituais pelos quais se pode tentar pensar sem identidade, eu ainda não estou convencido de que se consiga. Acho que precisamos tentar reconceitualizar o que as identidades podem significar nesta situação mais diversa e pluralizada.

Isso nos leva de volta a algumas das questões mais profundas que as pessoas têm feito sobre identidade nas formas recentes de teorizar. Primeiro de tudo, nós somos lembrados da estrutura da própria "identificação". A identidade propriamente entendida, longe de ser a coisa simples que temos pensado que é (nós sempre no mesmo lugar), é uma estrutura que é sempre cindida. A história da identidade é uma história de fachada. Uma história de fachada por te fazer pensar que você está sempre no mesmo lugar, sendo que no fundo você sabe que está se movendo. O que temos aprendido sobre a estrutura do modo pelo qual nos identificamos sugere que a identificação não é uma coisa, um momento. Temos que reconceitualizar a identidade como um processo de identificação e isso é bem diferente. É algo que acontece no tempo, que não é nunca absolutamente estável, que é sujeito ao jogo da história e ao jogo da diferença.

Eu não quero entediá-los autobiograficamente, mas eu posso contar algo sobre o processo da minha própria identificação. Se penso sobre quem eu sou, vejo que - em minha longa experiência - tenho tido múltiplas identidades. E muitas das identidades que eu tenho tido eu apenas sei não por causa de algo profundo dentro de mim - o eu real mas por causa de como as outras pessoas me reconhecem.

Então, eu vim para Inglaterra nos anos 1950, antes da grande onda de imigração caribenha e do Subcontinente Asiático. Eu vim de uma família jamaicana respeitável de classe média. Quando eu voltei para casa no final dos 50, minha mãe, que era muito claramente dessa classe e dessa cultura, me disse "eu espero que eles não pensem que você é um imigrante lá!" Eu nunca tinha me pensado como um imigrante! E naquela hora eu pensei: bem, na verdade, eu acho que é isso que eu sou. Eu imigrei exatamente naquele momento. Quando ela me saudou, quando ela me disse "olá, imigrante", quando me falou para recusar isso e no momento da recusa - como tudo o que minha mãe me pedia para fazer - eu disse "Isso é o que eu sou! Eu sou um imigrante!". E eu pensei, finalmente, eu vim para o meu real eu. 
E então, no final dos anos 60 e início dos 70, alguém me disse: "essas coisas estão acontecendo no mundo político - eu suponho que você seja realmente negro". Bem, eu também nunca tinha me pensado como negro! E eu vou contar uma coisa, ninguém na Jamaica nunca pensou. Até anos 70, toda aquela população se experienciou de diferentes formas, mas nunca se chamou de negra. E, nesse sentido, o negro tem uma história e também uma identidade que é em parte formada politicamente. Não é a cor da sua pele. Não é dada pela natureza.

Outro exemplo: neste exato momento eu disse para o meu filho, que é resultado de um casamento misto, "você é negro". "Não", ele disse, "eu sou marrom". "Você não entende o que eu estou dizendo! Você está olhando para o significante errado! Não estou falando da cor que você é. As pessoas têm toda sorte de cor. A questão é se você é culturalmente, historicamente, politicamente negro. Isto é o que você é".

A experiência contradiz a noção de que a identificação acontece de uma vez por todas - a vida não é assim. Ela vai mudando e parte do que está mudando não é o núcleo do "eu real" interior, é a história que está mudando. A história muda sua concepção de eu. Outra coisa crítica sobre a identidade é que ela é em parte a relação entre você e o Outro. Somente quando há um Outro você pode saber quem você é. Descobrir este fato é descobrir e revelar toda a enorme história do nacionalismo e do racismo. O racismo é uma estrutura de discurso e uma representação que tenta expelir o outro simbolicamente apagá-lo, colocá-lo lá longe no Terceiro Mundo, na margem.

Os ingleses são racistas não porque odeiem os negros, mas porque eles não sabem quem são sem os negros. Eles têm que saber quem eles não são para saber quem são. E a língua inglesa é absolutamente repleta de coisas que os ingleses não são. Eles não são negros, não são indianos ou asiáticos, mas eles também não são europeus nem franceses ${ }^{2}$ e assim por diante. O Outro. Há um momento fantástico em Pele negra, máscaras brancas, de Fanon, quando ele fala como o olhar do Outro fixa-o em uma identidade. Ele sabe o que é ser negro quando uma criança branca puxa a mão da sua mãe e diz "Olha, mamãe, um homem negro". Ele diz "eu fui fixado naquele olhar". Esse é o olhar da Outridade. E não há identidade que esteja fora da relação dialógica com o Outro. O Outro não está fora, mas também dentro do $\mathrm{Eu}$, da identidade. Portanto, a identidade é um processo, a identidade é cindida. A identidade não é um ponto fixo, mas um ponto ambivalente. A identidade é a relação do Outro consigo mesmo.

\section{DIFERENÇA(S)}

Seria possível contar essa história também nos termos de uma concepção psíquica de identidade. Alguns dos mais importantes trabalhos que os psicanalistas - de Lacan em diante - e as feministas (em relação à identidade sexual) têm feito é mostrar a importância

\footnotetext{
${ }^{2}$ N.T.: Hall utiliza o termo Frogs, que é uma forma pejorativa de se referir aos franceses.
} 
da relação com o Outro. A construção da diferença como um processo, como algo que se dá no tempo, é algo que, o feminismo tem nos mostrado, nunca termina. A noção de que a identidade está completa em algum momento - a noção de que masculinidade e feminilidade podem se ver uma a outra como uma imagem de espelho perfeitamente refletida - é insustentável depois da mínima leitura de qualquer texto feminista ou depois da leitura dos Três ensaios sobre a teoria da sexualidade, de Freud.

Portanto, a ideia de que há identidade fora da representação - de que há um nós mesmos e uma linguagem pela qual nos descrevemos - é insustentável. A identidade está dentro do discurso, dentro da representação. Está construída em parte pela representação. A identidade é uma narrativa do eu; é a história que nós contamos sobre o eu para sabermos quem somos. Nós impomos uma estrutura nisso. $\mathrm{O}$ efeito mais importante dessa reconceitualização da identidade é o retorno sub-reptício da diferença. E agora precisamos pensar a identidade em relação à diferença. Há diferenças entre os modos pelos quais os gêneros são social e psicologicamente construídos, mas não há fixidez nestas oposições. É uma oposição relacional, uma relação de diferença. Estamos, então, em uma área conceitual difícil, tentar pensar identidade $e$ diferença.

Há duas noções diferentes de diferença operando. Há as grandes diferenças do discurso do racismo - negro e branco, civilizado e primitivo, eles e nós. No entanto, essa nova concepção de diferença está muito mais próxima da que se encontra em Derrida. Em Derrida você encontra uma noção de differance que reconhece a natureza interminável, contínua da construção do significado, mas esta também reconhece que há sempre o jogo da identidade e da diferença e sempre o jogo da diferença sobre a identidade. Você não pode pensar em uma sem a outra.

Veja, sempre houve na nossa vida uma política da identidade. Houve uma política da identidade em 1968 na qual os diversos movimentos sociais tentaram organizar-se politicamente dentro de uma identidade. Então a identidade de ser uma mulher era o tema do movimento feminista. A identidade de ser uma pessoa negra era a identidade do movimento negro. E nesse universo mais simples, havia uma identidade para cada movimento. Enquanto você estava nele, você tinha uma identidade. É claro que mesmo naquela época, todos nós nos movíamos entre estas identidades consideradas tão estáveis. Nós éramos amostras dessas identidades diferentes, mas mantínhamos a noção, o mito, a narrativa de que éramos realmente todos a mesma coisa. Esta noção de formas essenciais de identidade não é mais sustentável.

\section{O PROJETO THATCHER}

Então, como a gente pode pensar em identidade neste contexto? Eu quero dizer só uma coisa sobre como isto tem emergido politicamente no Reino Unido nos últimos dez anos. Eu me referi, em algum momento atrás, a uma concepção bastante estreita e exclusiva de inglesidade que repousa no centro do projeto político do thatcherismo. Quando eu comecei a escrever sobre thatcherismo pela primeira vez no início dos anos 70, eu pensava que era um grande projeto econômico e político. Foi apenas mais recentemente que eu percebi o quão profundamente ele está enraizado em uma certa 
concepção exclusiva e essencialista de inglesidade. O thatcherismo está em defesa de uma certa definição de inglesidade. A Inglaterra não foi à Guerra das Malvinas ${ }^{3}$ inadvertidamente. Ela foi porque havia algo como uma conexão com o grande passado imperialista, com o império, com o leão cujo rabo não podia ser puxado, com o pequeno país que se levantou contra o grande ditador. É um jeito de viver miticamente todos os grandes momentos do passado inglês novamente. Bem, acontece que dessa vez teve que acontecer no Atlântico Sul, milhas distantes de qualquer coisa - em um pequeno canto do globo que a maioria dos ingleses não pode identificar no mapa. Esta é a frase mais famosa de Marx: "A primeira vez é história, a segunda é farsa". E a terceira vez é uma extremamente longa viagem ao Atlântico Sul. Este é o momento de declínio que é sempre um momento de perigo nas culturas nacionais.

\section{O RETORNO DO REPRIMIDO}

É uma parte bastante significativa do projeto de Thatcher tentar restaurar a identidade que no ponto de vista deles pertence à Grã Bretanha - Great Britain, Inc., Ltd. - uma grande empresa, a Grã Bretanha restaurada em uma potência mundial. Mas exatamente neste momento de tentativa de restauração simbólica das grandes identidades inglesas que tinham dominado e controlado o mundo por três ou quatro séculos, vem empoleirar-se em casa alguns outros britânicos. Eles vêm da Jamaica, Paquistão, Bangladesh, Índia - toda aquela parte do mundo colonial que os ingleses, somente nos anos de 1950, decidiram que podiam dispensar. Somente neste exato momento, quando decidiram que podiam nos dispensar, nós pegamos o banana boat e voltamos diretamente para casa. Voltamos dizendo "você disse que esse é o pais materno. Bem, eu cheguei em casa". Nós agora permanecemos como uma lembrança constante dessa história esquecida, suprimida, escondida. Toda vez que eles andam na rua, algum de nós - algum do Outro está lá. Nós estamos lá, dentro da cultura, indo a suas escolas, falando sua língua, tocando sua música, andando pelas suas ruas, parecendo que nós somos donos de uma parte da grama, parecendo que pertencemos àquele lugar. $\mathrm{Na}$ terceira geração os negros começaram a dizer "Nós somos os negros britânicos". Afinal, quem somos nós? Nós não somos mais jamaicanos. Temos uma relação com aquele passado, mas não somos mais aquilo inteiramente. Dá para ver que debates sobre as questões de identidade estão no centro da vida política na Inglaterra hoje.

\section{ETNICIDADES: VELHAS E NOVAS}

O que tudo isso que eu estou falando tem a ver com etnicidade? Eu deixei a questão da etnicidade por último porque etnicidade é o modo pelo qual eu quero repensar as relações entre identidade e diferença. Eu quero argumentar que etnicidade é o que nós todos requeremos para pensar estas relações. O que eu quero dizer com isso? Não há forma, me parece, pela qual as pessoas do mundo podem agir, falar, criar, vir das margens

\footnotetext{
${ }^{3}$ N.T.: No original, Falklands War.
} 
e dizer, começar a refletir sobre sua experiência se não vierem de algum lugar, elas vêm de alguma história, herdam certas tradições culturais. O que temos aprendido da teoria da enunciação é que não há enunciação sem posicionamento. Você tem que se posicionar em algum lugar para dizer qualquer coisa. Portanto, não podemos evitar que o sentido de nossa própria posição está conotado pelo termo etnicidade. E a relação que os povos do mundo agora têm com seu próprio passado parte, é claro, da descoberta de sua própria etnicidade. Eles precisam honrar as histórias escondidas de onde vieram. Eles precisam entender as línguas que eles não foram ensinados a falar. Eles precisam entender e reavaliar as tradições e heranças de expressão e criatividade cultural. E, neste sentido, o passado não é apenas uma posição de fala, mas é também uma fonte absolutamente necessária do que se tem a dizer. Não há forma, na minha maneira de ver, na qual esses elementos de etnicidade, que dependem do entendimento do passado, do entendimento de suas raízes, possam ser evitados.

Mas, por outro lado, aí entra o papel da diferença. Este é o reconhecimento de que nossa relação com o passado é bastante complexa, não podemos arrancar do nada de onde estava e simplesmente restaurá-lo. Se você perguntar ao meu filho, que tem dezesseis anos e que nasceu em Londres, de onde ele vem, ele não pode te dizer que ele veio da Jamaica. Parte de sua identidade está lá, mas ele tem que descobrir essa identidade. Ele não pode simplesmente tirar da mala, jogá-la na mesa e dizer "Isso é meu". Não é uma essência desse jeito. Ele precisa aprender a contar a si mesmo a história de seu passado. Ele precisa interrogar sua própria história, reaprender essa parte de si que tem um investimento nessa cultura. Por exemplo, ele está aprendendo escultura em madeira, e para isso ele teve que descobrir as tradições de escultura de uma sociedade na qual ele nunca viveu.

Portanto o tipo de etnicidade que eu estou falando não é simples, essencial - é construída. É construída na história, é construída em parte politicamente. É parte de uma narrativa. Contamos a nós mesmos as histórias de nossas raízes para ter contato, criativamente, com isso. Então essa nova forma de etnicidade - as etnicidades emergentes - tem uma relação com o passado, mas é uma relação que é parte pela memória, parte pela narrativa, que tem que ser recuperada. É um ato de recuperação cultural.

No entanto é também uma etnicidade que tem que reconhecer sua posição em relação à importância da diferença. É uma etnicidade que não pode negar o papel da diferença na descoberta de si mesma. Vou contar uma história simples e rápida para mostrar o que eu quero dizer. Cerca de dois anos atrás eu estava envolvido em uma exposição fotográfica que era organizada pelo Commonwealth Institute na Inglaterra e a ideia por trás disso era muito simples. A fotografia é uma das linguagens pelas quais as pessoas falam de seu próprio passado e sua própria experiência e constroem sua própria identidade. Um grande número de pessoas nas sociedades marginalizadas do Commonwealth Britânico tem sido objeto da representação de outra pessoa, não o sujeito de suas próprias representações. O propósito dessa exibição era capacitar algumas pessoas dessas regiões a usar o meio criativo da fotografia para falar e abordar suas próprias experiências - dar poder a suas etnicidades.

Quando se vinha para ver a exposição, se via duas coisas ao mesmo tempo. Primeiro, o enorme entusiasmo das pessoas que foram capazes de falar pela primeira vez 
sobre o que sempre souberam - falar sobre sua cultura, suas línguas, seu povo, sua infância, a topografia em que cresceram. As artes em nossa sociedade têm sido transformadas por novos discursos de sujeitos marginalizados vindos à representação pela primeira vez. Mas nós também estamos vendo algo mais que não estávamos preparados para ver. Por estes enclaves étnicos locais, o que eles também queriam falar era sobre o mundo todo. Eles queriam contar como eles foram do Village para Manhattan. Eles não estão preparados para serem arquivistas étnicos pelo resto de suas vidas. Eles não estão preparados somente para ter algo a dizer sobre marginalização para sempre. Eles têm uma participação no todo da história dominante do mundo, eles querem reescrever a história do mundo, não somente contar suas pequenas histórias. Então eles usam a fotografia para nos dizer sobre as enormes imigrações do mundo e como as pessoas agora se movem sobre como todas as nossas identidades são construídas a partir de uma variedade de diferentes discursos. Precisamos de um lugar para falar a partir de, mas não mais falamos sobre etnicidade de uma forma estreita e essencialista.

Esta é a nova etnicidade. É uma nova concepção das nossas identidades porque não perdeu o lugar e a base de onde podemos falar, mas este lugar não é mais uma essência. Ele quer abordar uma variedade de experiências muito mais ampla. É parte da enorme relativização cultural do globo, que é o feito histórico - em parte terrível como tem sido do século XX. Estas são as novas etnicidades, as novas vozes. Elas não estão nem presas no passado e nem são capazes de esquecê-lo. Nem totalmente a mesma, nem totalmente diferente. Identidade $e$ diferença. É um novo acordo entre identidade e diferença.

É claro que ao lado das novas etnicidades existem as velhas etnicidades e a união das velhas identidades essencialistas com o poder. As velhas etnicidades ainda têm o domínio, ainda têm o governo. De fato, como eu tentei sugerir quando me referi ao thatcherismo, conforme elas são relativizadas sua propensão para devorar tudo cresce. Elas só podem ter certeza de que realmente existem se consumirem todo o resto. A noção de identidade que sabe de onde vem, onde é seu lar, mas que também vive no simbólico - no sentido lacaniano - sabe que não se pode voltar realmente para casa. Você não pode ser outra coisa além do que é. Você deve encontrar o que você é no fluxo do passado e do presente. Essa nova concepção de etnicidade está agora lutando por todo o globo de diferentes maneiras contra o perigo presente e a ameaça da velha etnicidade perigosa. Esta é a aposta do jogo.

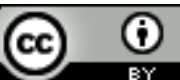

Este texto está licenciado com uma Licença Creative Commons Atribuição 4.0 Internacional. 